\title{
Erratum to: Enterprise Inter- and Intra-Organizational Integration
}

\author{
Kurt Kosanke ${ }^{1}$, Roland Jochem ${ }^{2}$, James G. Nell ${ }^{3}$, and Angel Ortiz Bas ${ }^{4}$ \\ 1 CIMOSA Association e.V., Germany \\ ${ }^{2}$ Fraunhofer Institute for Production Systems and Design Technology (IPK), \\ Germany \\ ${ }^{3}$ National Institute of Standards and Technology (NIST), USA \\ ${ }^{4}$ Polytechnic University of Valencia, Spain
}

\section{Erratum to: \\ K. Kosanke et al. (Eds.) \\ Enterprise Inter- and Intra-Organizational Integration \\ DOI: $10.1007 / 978-0-387-35621-1$}

The book was inadvertently published with an incorrect name of the copyright holder. The name of the copyright holder for this book is: (C) IFIP International Federation for Information Processing. The book has been updated with the changes.

The updated original online version for this book can be found at

DOI: $10.1007 / 978-0-387-35621-1$ 